Institute of $\mathbf{F}_{\text {ood and }} \mathbf{A}_{\text {gricultural }} \mathbf{S}_{\text {ciences }}$

\title{
Value of Pollination by Honey Bees ${ }^{1}$
}

\section{Malcolm T. Sanford ${ }^{2}$}

There's been a lot of talk over the years about the value of bee pollination to agriculture. Perhaps the best reference is what some call the "pollination Bible," S. E. MacGregor's book, Insect Pollination of Cultivated Crop Plants, Agricultural Handbook 496, published in 1976 by the Agricultural Research Service (ARS) of the United States Department of Agriculture. Unfortunately, this book is currently out of print, although it may still be available from some U.S. Government agencies.

The above volume is the source of the often-heard quotation that approximately one-third of the U.S. diet is directly or indirectly dependent on insect-pollinated plants. Unfortunately, this has been at best only a vague reference to the actual value of bees as pollinators, because few numbers were available to prove the point.

Dr. Marshall D. Levin, former director of the Carl Hayden Bee Research Center, for a long time chief bee scientist on the U.S. Department of Agriculture's National Program Staff, however, has published some hard facts, backed up by solid numbers on the honey bee's value to agriculture. Now bee scientists and beekeepers have something concrete to point to when asked about the value of bee pollination to agriculture. The bottom-line figure is almost 19 billion dollars, or 143 times the total value of honey and wax produced by bees.

Dr. Levin's figures are derived from analyses of bee pollination to fruits and nuts, seeds and fiber, and vegetable seed and animal production indirectly dependent on bee pollination. Of the 25 or so fruits and nuts, mentioned, apples and almonds lead the list with values of 757 and 473 million dollars respectively, followed by peaches (368), strawberries (288), cantaloupes (161) and watermelons (149). The value to citrus is 155 million dollars and to pickles (processed, 100, fresh, 116). In the seeds and fiber category, soybeans lead the way, valued at 1.3 billion dollars. This figure is considered conservative because only ten percent of potential soybean pollination is realistic! Sunflowers (410 million dollars), cotton (se, 57; lint 407) and alfalfa (114), and finally, vegetable seeds (60) follow in order of importance.

Of the five billion dollars accounted for by crops resulting from seed requiring bee pollination, alfalfa hay leads ( 4.9 billion), followed by onions ( 346 million) and cabbage and carrots at 175 and 161 million respectively. Cattle and calves are also considered by Dr. Levin to be indirectly dependent on bee pollination, because 60 percent of all hay fed to

\footnotetext{
1. This document is ENY-126, one of a series of the Entomology and Nematology Department, Florida Cooperative Extension Service, Institute of Food and Agricultural Sciences, University of Florida. Publication date: December 1992. Please visit the EDIS Website at http://edis.ifas.ufl.edu. Additional information is available at the Entomology and Nematology Department website located at http://entnemdept.ifas.ufl.edu.

2. Malcolm T. Sanford, professor, Entomology and Nematology Department, Cooperative Extension Service, Institute of Food and Agricultural Sciences, University of Florida, Gainesville, FL 32611.
} 
cattle and dairy herds is alfalfa. A conservative 10 percent potential value of hay fed to cattle and calves is 5.5 million dollars, while that responsible for liquid milk production is 1.6 million.

Dr. Levin published his article to show the relative value of bee pollination to U.S. agriculture and to communicate to entomologists, public officials and the general public the "real" value of the beekeeping industry which at present supplies much of bee pollination free of charge. As Dr. Levin says, "Although the total value of crops and commodities affected by the pollinating activities of bees has reached an impressive figure on a national basis, the beekeepers who supply most of this service receive very little monetary compensation for it. A study made by the U.S. International Trade Commission (1976) revealed that, of the total beekeeping incomes earned by 118 commercial beekeepers in various states during 1871-1975, the proportion derived from pollination fees averaged only 9.7 percent." Dr. Levin's article, "Value of Bee Pollination to United States Agriculture," was published in the Bulletin of the Entomological Society of America, Vol. 29 (4), pp. 50-51, 1984 and reprinted in American Bee Journal, Vol. 124 (3), 1984, pp. 184-186.

A more recent article provides further evidence of the potential value of honey bees as pollinator. It's entitled, "Bee Pollination and Productivity Growth: The Case of Alfalfa," and was written by A. L. Olmstead and Donald B. Wooten for the American Journal of Agricultural Economics, February 1987, pp. 56-63.

The authors' thesis is that the spread of commercial pollination has received little attention in the literature which analyzes the growth of U.S. agricultural productivity since World War II. This omission is serious, according to the authors, because by 1980 over fifty commodities, valued over $\$ 5$ billion, had become largely dependent on the honey bee to produce a commercial crop. The focus of the article is "... to elevate bees from an abstraction in an arcane literature on externalities to their rightful place as an essential $\operatorname{cog}$ in the growth of U.S. agricultural productivity."
Among many important crops like apples, melons, almonds, plums, prunes, pears, cherries, berries, pumpkins, squash, the authors say, yield would drop by over one half if honey bees were used only at the density associated with efficient honey production. In addition, honey bees have become essential to the production of commercial seeds for most vegetables, grasses and legumes, the value of which exceeds $\$ 10$ billion, including broccoli, cabbage, carrots, cauliflower, cucumbers, lettuce, onions, clovers, alfalfa and vetches. These specialty crops, the authors conclude, are even more dependent on honey bees than are fruits and nuts.

As the title suggests, the growth of the alfalfa industry in the western U.S. is used as a test case by the authors to prove their point. The authors claim that intensive bee pollination was the primary cause for a regional specialization in alfalfa beginning in 1949 due principally to phenomenally large gains in yield during the period. The value of the alfalfa industry is 50 percent greater than cotton, and only corn, wheat and soybeans are worth more.

A short history of the alfalfa situation reveals some of the same kinds of issues that beekeepers face today, and might provide ideas in developing a pollination service. The fair price for a pollination colony was guesswork at best. Because beekeeping was competitive with one of the lowest financial costs of entry for any type of agricultural enterprise, and hives could be moved fairly easily, growers only had to cover a beekeeper's opportunity costs. Many plans were conceived to compensate beekeepers ranging from so many dollars per beehive to a set moving fee plus a percentage of the crop in excess of some base figure. An innovative Valley Pollination Service (VPS) was also organized in Kern County, California specializing in renting hives to alfalfa seed growers. It not only facilitated contracting in a developing market, but also guaranteed quality of colonies and helped beekeepers insure against losses by spreading the risk of farmer default.

The authors' state in their summary that the alfalfa case study illustrates a number of propositions that are a common theme in U.S. agricultural development. Specifically, these are the importance of a network of decentralized scientific research 
stations in conjunction with the land grant college system which helped develop the methodology and trained those who become the innovators in the "Many other crops (besides alfalfa) also experienced significant growth of output with the introduction of commercially supplied bees, but as yet we know relatively little about the timing and extent of these changes."

"Estimating the Economic Value of Honey Bees (Hymenoptera: Apidae) as Agricultural Pollinators in the United States," written by E. E. and L. S. Southwick, Journal of Economic Entomology, Vol. 85, No. 3: pp 621-633, 1992 is another attempt to establish the real value of honey bee pollination for society. According to the authors, although beekeepers know the honey bee has value as a pollinating insect, the actual numbers are often obscured by many factors. They also state that about 400 agricultural crops on a worldwide basis and 130 in the U.S. are pollinated by both honey bees (Apis) and other bees. Perhaps the best estimated value of bee pollination is by Dr. Marshall Levin, retired director of the Tucson, Arizona Agricultural Research Laboratory (discussed elsewhere in this fact sheet). However, the authors conclude, this work did not include an estimate of contributions only by honey bees. More recent studies have estimated that $\$ 10$ billion is the correct figure for the honey bee contribution. In the past, honey bees have also been credited with pollination done by other bee species.

The authors suggest that it is especially important to know the value of honey bee pollination now. That's because populations are likely to be significantly affected by:

1. Mites that have recently been introduced and are spreading rapidly.

2. Diseases such as American foulbrood, chalkbrood and nosema that continue to take their toll.

3. Northward migration of Africanized bees directly affecting honey bees managed for agricultural pollination.

4. Increased use of insecticide, responsible for honey bee colony losses.
With this in mind, the authors have estimated demand functions for a long list of crops. They follow this with an appraisal of the societal value of honey bees for each. Leading the list are: almond; apple; cranberry; grape; grapefruit; lemon; orange; asparagus; broccoli; cantaloupe; honeydew melon; watermelon; and alfalfa, cotton and soybean seed. Their summary is that the annual benefit of the honey bee to U.S. agricultural consumers is on the order of $\$ 1.6-\$ 8.3$ billion, depending on whether honey bees have replaced (low value) or not replaced (high value) alternative pollinators. The authors further conclude that more study be applied to: (1) finding ways to reduce potential losses to the honey bee industry; and (2) improving management of alternate native pollinators. 